\title{
Innovation and Technology Management in Wind Energy Cluster
}

\author{
Wagner Sousa de Oliveira (Corresponding author) \\ Department of Economics, Management and Industrial Engineering, University of Aveiro \\ P.O. box 3810-193, Aveiro, Portugal \\ Tel: 351-915-591-902Ｅ-mail: wsoliveira76@gmail.com \\ António Jorge Fernandes \\ Department of Economics, Management and Industrial Engineering, University of Aveiro \\ P.O. box 3810-193, Aveiro, Portugal \\ Tel: 351-234-370-361Ｅ-mail: afer@ua.pt
}

$\begin{aligned} & \text { Received: October 20, } 2011 \\ & \text { Accepted: October 26, } 2011 \quad \text { Published: December 31, } 2011 \\ & \text { doi:10.5539/eer.v1n1p175 }\end{aligned}$ URL: http://dx.doi.org/10.5539/eer.v1n1p175

The research is financed by Foundation for Research and Technological and Scientific Development of Maranhão (FAPEMA) - Brazil and Economics Department of University of Aveiro.

\begin{abstract}
Innovation and technology management in wind energy industry is driven by policies and incentives due to their inherent characteristics such as high upfront costs, lack of level playing field but distinct advantages from energy security, environmental and social considerations. This paper makes an analysis of innovation and technology management in wind power industry, focusing on value chain and the interaction of technology and markets for contributing to recommendations on technology policy and management. This paper proposes a framework for analyzing the initial stage of diffusion of wind power systems, combining the use of various approaches, considering wind power system as a complex technology. The approach to the business system is used as an analytical framework, focusing on efficiency, effectiveness and criteria for development.
\end{abstract}

Keywords: Innovation and technology management, Wind energy cluster

\section{Introduction}

Renewable energy, combined with the rational and efficient use of energy, will be able to supply half of global energy demand by 2050. The report, "Energy Revolution - A Sustainable Path to a Clean Energy Future", concludes that the reduction of global $\mathrm{CO}_{2}$ emissions by $50 \%$ over the next 43 years is economically viable, and that the mass adoption of renewable energy sources also is technically possible - only lack the political support for this to occur. While the industrialized world needs to urgently rethink its energy strategy, the developing world should learn from past mistakes and build their economies from the beginning on a solid basis for a sustainable energy supply. A new infrastructure must be constructed to allow that to happen. The energy is a key factor in the evolution and development of human activities.

The concern for obtaining energy sources has been a constant. Throughout its history, the human being has gone through several periods in which different energy dominated matrices, such as biomass, coal and oil. Today, new alternatives are sought, encouraged, especially due to the energy crisis and the environmental damage caused by burning fossil fuels (Gipe, 1995). One alternative is the implementation of new clean energy - about the aspect of environmental pollution or reduction of $\mathrm{CO}_{2}$ emissions - when the use of renewable natural resources. Wind power provides a picture quite different from other Renewable Energy Technologies (TER), which already provides for technological maturity and scale of industrial production. This was the result of significant investments in R\&D and policy of creating a market through incentives in several countries, especially Germany, Denmark, USA, and more recently in Spain, among others (IEA, 2008b). Today this technology is about to become economically viable to compete with traditional sources of electricity generation, and there is great wind potential to be exploited in several countries (Alexandre, 2001; Vesterdal, 1992). There are opportunities for technological improvements and 
identified internationally that should lead to further cost reductions and allow for very ambitious goals for installation of power systems over the next 30 years. Half of the electricity consumed in the world could be generated from renewable sources, says the second edition of the study [R]evolution Energy: Prospects for a Global Sustainable Energy. Currently, only 13\% of world demand for primary energy is supplied by renewable sources (Cordeiro, 2008).

Technological innovation is fundamental for rendering the energy economy cleaner and more efficient with concomitant economic, developmental, and environmental benefits. The innovation literature highlights other important findings. Innovation is a product of complex systems, in which feedbacks from the different stages of the innovation chain and the ability to learn from market experience are crucial. Also, major innovations involve co-evolution of technologies and institutions that support them (Robert D. Perlack \& Shelton., 1996). The development and market diffusion of wind turbines was strongly supported by a variety of government policies including specific R\&D programs, construction incentives like investment subsidies and production incentives such as feed-in tariffs or tax exemptions. A major driver for the political support of wind power was the concern about environmental issues. The continuous growth in the electricity demand led to ever increasing ecological impacts and environmental hazards, which can be interpreted as reverse salient for the expansion of the system (Markard \& Truffer, 2006). Whereas some environmental problems like acid rain have been overcome by end-of pipe technologies, others like the depletion of fossil fuels or the emission of greenhouse gases call for renewable energy sources.

Technological advances have driven the long evolution of the energy sector, operating to increase energy's benefits while reducing its costs and risks. Such advances have expanded energy supplies, increased the efficiency of transformation of raw energy resources into desirable end-use forms, improved the availability and quality of energy services while lowering their monetary costs, and reduced the adverse environmental impacts that result from energy extraction, conversion, and use. But recent trends in the organization of the energy sector in many countries, combined with an increasing recognition of the urgency of traditional as well as new challenges facing it, have raised concerns about national and international capabilities to bring forth adequate innovations to meet those challenges in the decades ahead (Sagar \& van der Zwaan, 2006).

\section{Prospects for the Global Wind Energy}

The recent large increases in oil prices put the discussion on security of supply on the agenda and international energy policy. One of the reasons for the spike in oil prices is the progressive exhaustion of the supply of all fossil fuels - oil, gas and coal - and the consequent rise in production costs. The days of cheap oil and natural gas are coming to an end. Uranium, the fuel for nuclear plants, is also a finite resource. The reserves of renewable energy, on the other hand are technically accessible to all and abundant enough to provide for ever, about six times more energy than is consumed today in the world (Nick Loney, 2001; Zervos \& Kjaer, 2008).

Renewable energy technologies vary among themselves in terms of technical development and economic competitiveness, but there are a variety of options increasingly attractive. The renewable energy sources include wind, biomass, photovoltaic, solar collectors for water heating, geothermal, wave and hydroelectric. Among these are two characteristics in common: low emission of greenhouse gases and the use of virtually inexhaustible natural sources. Some of these technologies are already competitive - and should become even more - with investments in research and development, the possibility of commercial value in the market for carbon credits and on the other hand, the continuous increase in the price of fossil fuels. In parallel, there is enormous potential for reducing energy consumption, without implying a reduction in the provision of energy services. Studies show a series of energy efficiency measures that together can substantially reduce energy demand in industrial, residential and service sector (Flavin, 1999; SunMedia GmbH., 1999). The solution to our future energy needs lies in greater use of renewable energy sources, both for transport and for power generation (Heier, 1998). The report on The Prospects for the Global Wind Energy, the Global Wind Energy Council (GWEC, global forum for the wind energy sector, with a thousand and five hundred companies, organizations and institutions in over fifty countries) indicates that by 2050, a third of global electricity can be supplied by the wind. The capacity of wind turbines deployed on this scale would prevent one hundred and thirteen million tons of $\mathrm{CO}_{2}$ were released into the atmosphere in 2050. This report firmly places wind power as one of the most important energy sources for the twenty-first century. The capacity of energy production is already fifty-nine thousand megawatts and growing enough each year. According to the consolidated data in March 2010 by GWEC (GWEC, 2010) the global installed capacity in 2009 reached 158,505 MW, distributed according to Figure 1.

According to the DGGE (Directorate General for Energy and Geology) installed wind power in Portugal at the end of December 2009 stood at 3,566 MW spread over 195 parks with a total of 1,879 wind turbines throughout the 
Continental territory. About $37 \%$ of installed capacity is located in parks with a capacity equal to or less than 25 MW. Production in 2009 stood at 2231 hours equivalent per MW, with $72 \%$ of the energy generated in facilities with more than 2,000 hours in 2009. The districts with the largest installed capacity in December 2009, are Viseu, Castelo Branco, Coimbra, Viana do Castelo, Lisbon, Vila Real, Leiria, Santarém, Braga and Guarda (624, 470, 465, 351, 287, 272, 231 , 157, 151 and $150 \mathrm{MW}$ ) (DGGE, 2009).

With regard to the cost level is already achieved favorable due to the technological progress that has been in the wind energy industry. The availability of locations has also increased, although the population is against it "spoils the landscape." It is a solution that does not serve a large scale because of its intermittency and storage difficulties. In addition much space is required for installation. The climate change imperative demands nothing short of an energy revolution. At the heart of this revolution is a change in how we use, distribute and consume energy. The five key principles for this change are: (i) Implement renewable solutions, especially through decentralized energy systems, (ii) Respect the natural environment, (iii) Phase out dirty energy sources and unsustainable, (iv) promote equitable use of resources and (v) Decouple economic growth from fossil fuel consumption.

The largest wind turbines in the world, most of them are installed in Germany, with capacity of $6 \mathrm{MW}$. The cost of new systems, however, has stagnated in some countries in recent years due to the continuing increase in demand from manufacturers and considerable investment in improved technology and developing and introducing new systems. The result is that the learning factor observed for wind turbines built between 1990 and 2000 in Germany was only 0.94 . However, since the technical developments have provided increased production costs of electricity generation tend to decrease. It is expected a greater potential for cost reduction, with the learning rate correspondingly higher (Nakicenovic, 1998). While the report World Energy Outlook 2004 the IEA expects global wind capacity grows only to $330 \mathrm{GW}$ by 2030 , the World Energy Assessment of the United Nations provides an overall saturation level of about 1,900 GW for the same period. Since the 2006 version of the Global Wind Energy Outlook projects a global capacity around $3,000 \mathrm{GW}$ by 2050 . An experience curve for wind turbines is derived from a combination of existing learning factors observed with expected high growth in the market, guided by the Global Wind Energy Outlook, indicating that the costs for wind turbines will be reduced by around $40 \%$ until 2050 .

The options for renewable energy technologies available today have marked differences in terms of technical maturity, costs and potential for development. While hydropower has been widely used for decades, other technologies such as biomass gasification, still need to open the way to economic maturity. Some renewable sources, due to its very nature, such as solar and wind provide a variable supply, requiring coordination controlled by the grid. But, although in most cases are decentralizing technologies - its power is generated and used locally by consumers - the future may be used on a large scale, in the form of coastal wind farms.

The key advantages of wind energy are that it is clean (it produces no emissions and physical disruption of the environment can be minimized), it is reasonably inexpensive, and technological advance is yielding rapid efficiency gains, causing its price to fall quickly. The key disadvantage of wind energy is that wind farms are often considered unsightly, and can pose a potential threat to migratory birds. Other often cited disadvantages are wind's intermittency, and that the most attractive wind sites in terms of production capacity are often not near urban areas, requiring investment in transmission lines (Schilling \& Esmundo, 2009).

\section{Organizational Model in the Wind Energy Industry}

Wind power systems are type of CoPS (Complex Product System) which are high-cost, engineering-intensive systems and never mass products for the final consumers. They are designed and produced on a project basis as one-offs for professional business. Unlike the final consumer, intermediate customers are intimately involved in the innovation process throughout the life cycle of the project. Technological accumulation is generated by the design, building and operation of the complex product system. The incremental improvement of technological improvement in complex product systems comes along as technological trajectory and they diffuse throughout the actor of best practice methods in design, manufacturing and construction (Davies \& Hobday, 2005; Hobday, 1998).

Wind power system also has multiple aspects such as technological system (Hughes, 1983), which receives the influence of non-physical artifact such as institution. To evaluate the effect of technology and policy in the diffusion process and recognize the mechanism which promotes this process is also our concern. In this paper, we propose a dynamic diffusion model in which supply and demand of innovations make progress by coexisting with existing energy system (e.g. fossil power station, nuclear power station). It is supposed more rational that wind power is carried out in complementing the existing energy system rather than supplying electric energy 
independently.

This diffusion model of wind power is shown in Figure 2. To promote the diffusion of wind power, economic factor is essentially important. For example, investment costs should be collected by electricity obtained by wind power. In order to collect investment cost, equipments have to be enlarged and we should pursue raising economies of scale. While the demand level about quality and safety is high in the market for using electricity obtained from wind power, the value is relatively low. Although its electricity is now approaching to generate a profit, there are several problems in economical efficiency under the present circumstances. At first, the battle against global warming initiates the supply target of innovation (wind power), which could coexist with other existing energy system and help to reduce global warming. Government, industry and academic organizations are involved and the acts which could solve the above-mentioned problems are taken into consideration institutionally since it would not be a problem attributed only to industry.

The emphasis of technological development is put on safety, improvement in performance and reduction of manufacturing cost so as to penetrate this technology in the market by industry-government-academia collaboration. Industry raises the knowledge in connection with manufacturers to get over the critical point lying ahead. Then learning effect reduces the installation costs of wind power systems. In parallel, government could support the installation of wind power systems to get over the critical point so that the wind power systems have the competitive edge by which running cost can compete with other existing energy system on the basis of net present value. Even if a wind power system is not able to link directly with the existing energy system economically, the alternative systemic measures that avoid some critical points are taken into consideration in this institution, from the stand point of a battle against global warming or energy security (D. Mowery \& Rosenberg, 1979, 1998).

Often, collaborative R\&D needs public support. The EU through the Sixth and Seventh Framework Programmes for research and development introduced the concept of technology platforms. These provide an opportunity for collaboration between a wide range of stakeholders, including industry, academia, politicians, the public, etc. In the present technology platforms in the renewable energy sector exist for solar photovoltaic, wind power, solar water heating and biofuels (IEA, 2010).

Rogers (1982) analyzed the diffusion problem most vigorously from a sociological standpoint and he showed the model of the innovation-decision process as a process through which an individual passes and the diffusion curve with labeling for the five adopter categories. Rogers explained the relation between the influence of communicating information and adoption decision in the earlier phase as well as the characteristics of adopters and the relative time progress of diffusion in the latter phase. However, Rogers' model is taking into consideration only for the diffusion process of the demand side. In the case of the standard concept which is unified in generating diffusion of innovations, Rosegger (1996) mentioned that standard versions of a new technology do emerge, 'bugs' are worked out by early adopters, market results are reported, and thus the quality of information which is available to later adopters improves. However this assumption is not demonstrated with the on-going phenomenon of supply and demand side (Ortt \& van der Duin, 2008).

Institutions are broadly defined by economists and innovation theorists as social, political, and economic organizations that determine the working environment for systems to develop within. Institutional economists emphasize the role that institutions play on the outcomes of economic operations more than their neoclassical-school counterparts. How important an industry's working environment is when examining technology development and cycles. For instance, the direction of domestic technology innovation can be influenced by knowledge spillovers due to international trade, the flexibility and ease of information flow from the university system, and the structure and patent making ability of the legal system. These institutional dynamics can vary widely across countries, both within and across different development levels. As such, global rates of technology development do not always imply similar rates of technology diffusion in particular domestic markets (Kobos, Erickson, \& Drennen, 2006).

The types of institutions influencing innovation, and ultimately technology diffusion, have been categorized as horizontal, nonmarket, and vertical. Horizontal institutions include those in which large technical interdependencies exist between products or organizations. Positive feedbacks can emerge between horizontal institutions as, for instance, RD\&D in one industry can lead to innovation or increased market potential in the other. In renewable energy technology, horizontal manufacturing structures may be necessary to successfully penetrate the market. For example, energy efficient home construction would benefit from well-designed solar thermal water heating systems. Nonmarket institutions are designed for goals not explicitly focused on short-run profits. These include professional societies, governmental agencies, and university-level research centers. These institutions 
often provide the necessary basic research and generic market promotion for incubating new technologies. They are often designed as subsidies to industry development and their effectiveness is often dependent on political goals and agendas when "society has found it necessary to supplement the usual market mechanism by additional institutions" (Mohan Reddy, Aram, \& Lynn, 1991).

Government and other organizing entities can often work to administer a coordination system. Figure 3 illustrates a conceptual framework for learning between individuals (e.g. workers and groups of workers) and the organization as a whole. The solid arrows represent flows of knowledge spillovers; the dashed arrows represent knowledge feedbacks. These feedbacks reinforce the role of knowledge stock solidarity (standardization) and quality control. For example, a knowledge spillover or 'feed forward' from the organizational level to the individual level can include implicit on-the-job training. While a feedback from this knowledge transfer (generation) would include suggestions and discussions, these individuals have with the management directing the organizational training programs and work environments.

Today, wind power is often subsidized, but it is approaching a cost level that makes it economically attractive compared to established energy production methods, assuming good wind conditions. As the experience curve of electricity produced by wind turbines is not entirely flat - a proposed ratio of 0.91 according to Neij (1997).

Cost reduction effects are specified as a three-parameter functional form, which by design permits the determination of optimized levels of R\&D support for a given technology (Miketa \& Schrattenholzer, 2004). The experience curves and bottom-up assessments of wind turbines indicate that further cost reductions will be possible in the future. (However, these cost reductions cannot be seen in the price development path of wind turbines at present). In general, the results show incremental cost reductions for both on-shore and off-shore wind turbines, and the reduction in the cost of wind-generated electricity will be greater than the reduction in the cost of wind turbines. Bottom-up assessments support an incremental development path of wind turbines - which may be reflected in an extrapolation of the experience curve-i.e. using a learning rate of approximately $10 \%$ for both on-shore and offshore wind turbines. To illustrate the greater cost reduction identified for generated electricity (including efficiency improvements and reduction of operating and maintenance costs), a higher learning rate should be used, e.g. a learning rate of $15 \%$ for wind turbines placed in less windy areas and a learning rate of $20 \%$ for off-shore wind turbines and wind turbines placed in windier areas. A restriction on further cost reductions in wind generated electricity will arise due to the limitation of favorable sites, as many of the best sites for wind turbines have already have been used. However, this will be a greater problem in countries that have already invested in large numbers of wind turbines. Due to the consensus on incremental improvement of wind power, a sensitivity range of $72 \%$ of the learning rate is suggested (Neij, 2008). Wind energy has grown a lot over the last years and this spectacular growth has attracted a broad range of players from across the industry value chain - from local, site-focused engineering firms to global, vertically-integrated utilities (see Figure 4).

Since Europe's surge in 2005 to an annual market of over $6.5 \mathrm{GW}$ of new capacity, the industry's value chain has become increasingly competitive as a multitude of firms seek the most profitable balance between vertical integration and specialization (EWEA, 2009b). More and more utilities take position on the wind energy value chain to comply with national renewable targets, and/or to take the initiative of seeking international expansion with this newer generation technology. Large-scale utilities have thus started to build sizeable project pipelines with long-term investment plans what lead to an overall scaling up of the sector. To maximize profitability, utilities have steadily migrated from risk-averse turnkey project acquisition, to greater vertical integration with in-house teams for development and operations and maintenance (O\&M). Strategies devised by these players for meeting their objectives have largely depended on their experience in the sector as well as on their desire to expand geographically. At the same time a market remains for independent players able to contribute development skills, capital and asset management experience.

As a result, Europe's wind energy value chain is currently shifting as asset ownership is redistributed, growth is sought in maturing markets and players seek to maximize scale on an increasingly pan-European stage. Utilities build up GW-size portfolios, through their own strategy initiatives or government prompting. IPPs seek to compete for asset ownership in booming Western European markets. In general, development activity continues to shift towards new regions in the east. The proliferation of players looking to develop, own or operate wind farms has pushed competition to a new level, underlining the key elements of local market knowledge, technical expertise and financial capacity as crucial to positioning on the value chain. Before utilities began adopting wind energy, vertically-integrated independent power producers (IPPs) started aggressively exploiting wind turbine technology to improve their positioning. There are two main types of IPP in Europe (EWEA, 2009b):

- integrated IPPs, which have capabilities across the project development value chain and exploit these for 
maximum control and returns on their project portfolio,

- wind project buyers, which tend not to play a direct role in the development of wind plants in their portfolio as these firms are often financial investors, rather than energy players.

The number of these players that are active has continuously increased as utilities have sought acquisitions among this field of asset and pipeline holding competitors, though those that are already a significant size may be positioned for long-term growth. In terms of development, integrated IPPs are continuing to expand internationally, through green field project development and acquisitions, in order to compete with utilities. Players with strong holds in Spain, France or Germany consistently look for growth in Eastern Europe, while some are also taking the plunge offshore. More risk-averse IPPs are seeing the number of quality projects available for acquisition in mature markets continues to dwindle.

As wind power owners, IPPs are facing harder competition from utilities as several project portfolios have been acquired in markets such as Spain, Germany, France and the UK. IPPs generally have higher capital costs than utilities and those that can create assets organically through development on their own are generally better positioned to enlarge their portfolio. As asset managers on the value chain, integrated wind IPPs and project purchases are distinctly different, with integrated players increasingly focusing on O\&M to maximize asset values. The boom in MW additions in the last years means many turbines are coming out of their warranty periods, requiring IPPs to make key strategic decisions on how to manage their installations.

In the US, utilities have been, from the beginning on, the main players in the wind energy market. The value chain of a component producer like the China Wind Energy Inc. looks as the following in Figure 6.

A less well understood feature of innovation processes is the intermediate stage between demonstration and diffusion that can be considered a market formation or 'early' deployment stage (often referred to as niche markets).(Anadon \& Holdren, 2009). Governments can play a crucial role creating initial markets; in doing this, governments can encourage reductions in costs, improvements in quality and functionality, and overall a better definition of the product for the customer (K. S. Gallagher, Anadon, Kempener, \& Wilson, 2011).

\section{Trends in R\&D for Wind Energy}

The beginning of the process is the Research and Development (R\&D), followed by demonstration and pilot production. This leads to early market introduction and finally, market diffusion. While different RETs are at different phases of market development, the research in diffusion analysis in renewable energy sector points towards the following approaches (Rao \& Kishore, 2010).

Empirical analysis of the historical development, current status, and future expectations for wind energy electrical power generation (i.e. onshore power generation) can be summarized as a 3-stage empirical industry life cycle illustrated in Figure 7, featuring three generic Stages of Exploration (or Development), Acceleration (or Dominant Design), and Maturation.

The change in policy to support private research - as opposed to collaborative research in the public domain - is likely to increase the influence of market forces on the choice of the project - and therefore the choice of technology. While this may be beneficial in terms of short-term deployment of new renewable technologies (RETs) alone, this may mean less opportunity that might exist to regulate the support given to specific technologies. If the trend appears in the field of renewable energy, it is likely that brings a short-term perspective, possibly reducing the support for RD\&D in technologies that are considered to have a great potential long-term, but are still relatively distant from the market, compared with more mature alternative (IEA, 2008a).

The European Technology Platform for Wind Energy (TPWind) identified as thematic areas for R\&D in wind energy for the next 30 years, the following aspects (IEA, 2010; TPWind, 2010a) as shown in Table 1.

It is noteworthy that efforts RD\&D already have excellent results, such as core R\&D engineering at the University of Risoe, Denmark, successfully completed the first practical tests of a new wind turbine - the gigantic fan responsible for energy generation wind - that can anticipate and react to changes in the wind by optimizing the generation of electricity. The results show that this system can predict the wind direction, wind intensity and even turbulence. With this, it is estimated that a future generation of wind turbines may increase energy production and at the same, reduce extreme loads that impact on their lifetime.

The system added to the wind turbine is a kind of laser anemometer, which scientists call "LIDAR of wind". LIDAR (Light Detection And Ranging) is a kind of "radar light", which uses a laser beam to detect the spatial distribution of temperature and humidity in the atmosphere. It likes a radar sends radio waves and measure their reflections, a LIDAR sends light waves. The "eco" in this case, this wave is the reflection of light by different 
layers of the atmosphere. The incorporation of LIDAR means that wind turbines are now able to "see" the wind through the detection of variations in air mass. In predicting the wind to reach the next moment, the turbine can optimize their position and adjust the pitch of its blades for wind to be used more efficiently and last longer than the turbine. The engineers say the laser technology increases energy production by up to $5 \%$, mainly because it allows the use of longer blades. For a wind turbine with capacity of $4 \mathrm{MW}$, this represents a financial gain of $\$ 200,000$ per year (DTU, 2010). LIDAR system can be used to enhance the durability of the blades by allowing them better cope with the irregularities in the wind. In a second step, it becomes possible to manufacture blades longer. This will increase the production of energy and make wind electricity competitive. The wind turbine industry is booming, it is expected to grow tremendously in coming years, thanks to the global focus on renewable energy and in response to climate changes (IEA, 2010).

Finally, it is necessary that all countries have access to technologies that enable them to build the most efficient new power plants and industrial facilities and install energy efficient equipment. Much of the development of this technology is currently being undertaken within the OECD countries, but most of its deployment will need to be elsewhere (Kim B, 1985). As example of a network which can help in technology development deployment is the IEA Implementing Agreements (in which both member and non-member countries work and co-operate), which provide a framework for joint research projects, discussion of specific technology issues and information exchange (Energy Technologies at the Cutting Edge, IEA, 2007).

According to H.J. Wagner (2009) to promote wind energy, the research needs need to be identified and the research work carried out. Initially, there are such environmental and social challenges as integration into the landscape, noise impact, bird flight paths, life cycle analysis and sustainability. And of course, wind turbine and component design have to be improved continually, i.e. basic research in aerodynamics, structural dynamics, dynamic forces, new materials, feasibility studies into new systems, generators using permanent magnets, gear boxes, etc. For planning and building wind turbines and wind farms, commonly accepted certification procedures must be formulated and standardized.

Governments, industry, research institutions and the wider energy sector will need to work together to achieve this goal. Best technology and policy practice must be identified and exchanged with emerging economy partners, to enable the most cost-effective and beneficial development. The technology road map for some of the most important technologies (wind energy) developed by the International Energy Agency (IEA) (IEA, 2009).

At the industry level, two methods to track the diffusion of wind turbine technology provide some insight. If technological change is occurring in wind turbines, we would expect that the cost of electricity from these turbines is decreasing, since cost is the performance characteristic about which users care most. Additional insight is gained from further exploring the trend of decreasing cost of electricity. The three primary means of reducing the cost of electricity from wind turbines are (1) reducing the capital cost of the turbine, (2) reducing operations and maintenance (O\&M) costs, and (3) generating more electricity without an offsetting increase in either capital or O\&M costs (Loiter \& Norberg-Bohm, 1999).

\section{Structures and Technologies to Support Innovation in Wind Power}

As currently understood, then, technological innovation is characterized by multiple dynamic feedbacks between different stages of the process; as Fri (2003) states, "the process of innovation is typically incremental, cumulative, and assimilative." It is nonetheless often useful for analytical and prescriptive purposes to treat the stages separately, and we frequently do so in this article. The stages of energy technology innovation to be considered comprise fundamental research, applied research, development, demonstration, pre-commercial and niche deployment, and widespread deployment (often also called diffusion). Technology transfer between countries is often envisioned as a part of diffusion, but it can also occur at earlier stages (Kelly Sims Gallagher, Holdren, \& Sagar, 2006).

The wind energy market surpasses its own record every year. The market growth rates are in the same range of technologies such as high technology (internet, phone and so on). Europe leads the world in terms of facilities and production, with most of the ten largest manufacturers of being European. A popular misconception is to consider wind power as a mature technology, where R\&D efforts are not necessarily needed. As a result, there is a risk of progressive loss of European leadership, as demonstrated by recent developments in wind energy sector: (i) High demand has increased the time of delivery of wind turbines and the prices of raw materials like steel and copper have increased in recent years, which means that the cost of wind turbines has increased and (ii) Although most manufacturers of wind turbines is still Europeans, two Chinese companies (Goldwind, Sinovel) and an Indian company (Suzlon) entered the market (IEA, 2010).

The private sector in funding research is significant, but exact figures are hard to find. Many companies can invest 
in the region of 3-5\% of revenues in research. In some cases, the RD\&D intensity is even greater. In Europe, after the start of the Technology Platforms for individuals and groups of technologies, the private sector is being encouraged to interact with the public sector, especially in long-term research; the intention is that private companies can share the investment with the public sector.

The European Technology Platform for Wind Energy (TPWind) is the indispensable forum for the crystallization of political and technological research and development paths for the wind energy sector, as well as a new opportunity for informal collaboration between the Member States, including the least developed in terms of wind energy.

The aim is to identify areas of TPWind greater innovation, research new and existing development tasks. These, then, to be prioritized based on urgency of the technology sector; the main objective being global (social, environmental and technological) is cost savings. This will help achieve the objectives of the EU in terms of renewable energy production. The platform is to develop coherent recommendations, detailing specific tasks, approaches, participants and the necessary infrastructure within the private investment in R\&D as well as Member State and EU programs, such as FP7. TPWind will also assess the overall funding available for this work, from public and private sources (TPWind, 2010b).

Wind power is the technology leader in renewable energy. Having regard to the right support could provide up to $28 \%$ of EU electricity by 2030 . However, this target will be achieved if the sector and policy makers continue to think in the short term. Long-term, strategic technology and policy research are fundamental: TPWind facilitates the development of effective and complementary national and EU policy to build markets, and a collaborative strategy for the development of technology. Your ultimate goal is to reduce costs to parity with cheaper technologies for alternative generation of electricity (TPWind, 2010b).

TPWind is composed of stakeholders from industry, government, civil society, R\&D institutions, financial organizations and most of the energy sector in the Member State and EU. It is unique: the only body with sufficient representation or "critical mass" of knowledge wind and specific experience to be able to fully understand and map the paths and realistic priorities for policy and technology R\&D, taking into account the wide range of needs the sector. In parallel, the European target of 20 percent of energy production from renewable sources poses new challenges. In its recently published Strategic Research Agenda, the European platform for wind energy, TPWind proposed an ambitious vision for Europe and viable. In this view, $300 \mathrm{GW}$ of wind power capacity would be delivered in 2030, representing up to 28 percent of EU electricity consumption. To implement this vision, an average of 10 to $15 \mathrm{GW}$ of additional capacity will be manufactured, delivered and deployed in Europe each year. This is equivalent to more than 20 turbines of $3 \mathrm{MW}$ to be installed on each day (GWEC, 2010; TPWind, 2010b).

Moreover, the vision TPWind includes a sub-goal of wind power represents about 10 percent of EU electricity consumption by 2030 . They propose an intermediate step of the execution of $40 \mathrm{GW}$ by 2020 , compared to $1 \mathrm{GW}$ today. In this sense, $R \& D$ is needed on two fronts:

1) An efficient implementation of TPWind vision for wind energy, supporting the implementation of european goals and,

2) Ensuring European leadership in the long term through technological leadership.

According to Figures 2 and 3 energy policy can influence the development of technology and capturing market (marketing), through the interaction of three main types of policies that target families or subsets of these technologies in progressive stages of technological maturity:

- $\quad$ Policy Research, Development and Demonstration (RD\&D);

- Policy deployment market (also called policy of support or promotion), and

- General Policies of the energy market.

As featured in Figure 5 the structure of TPWind, where the issues raised by themes, are concentrated in areas where improved technology leads to significant cost reductions.

Through a strategic research agenda, TPWind encourages Member States, EU institutions and the wind industry to intensify research efforts in accordance with market needs, in view of medium and long term. TPWind encourage research results in the long term, taking into account that new prototypes for wind energy are being developed.

For Kaldellis, \& Zafirakis (2011) what is important to consider is that for the aforementioned goals to be realized, $R \& D$ targets set must be put forward by the wind energy industry, with the main directions and actions to be taken including the following: 
- New wind turbines need to reduce their overall costs

- Large scale turbines of 10-20 MW going offshore (R\&D programs for prototypes already initiated)

- Improved design and reliability of components (Testing facilities to assess efficiency and reliability of wind turbines)

- Development of innovative logistics (Cross industrial programs)

- Deeper waters and larger turbines for offshore

- Development and industrialization of support structures for sea installations, both fixed and floating (Structure concepts to be developed and tested at different depths and under different conditions)

- Achieve grid integration for even greater wind energy penetration

- Introduction of large-scale energy storage systems and high voltage alternative and direct current (HVAC-HVDC) interconnections (Offshore farms connected with more than one grid, long distance HVDC, $\mathrm{R} \& \mathrm{D}$ of energy storage systems)

- Resource assessment and spatial planning

- More sophisticated assessment of wind resources (High quality measurements and databases for wind data as well as short-term wind speed forecasting with the use of neural networks)

- Spatial planning through social and environmental considerations (Development of planning tools and methodologies)

It is necessary to clarify the energy sector, in others words, wind energy industry is a technology cluster. Another aspect of importance is the concept of technology clusters. This is based on the fact that a technology does not develop alone but is related to and depends on other technologies as well as infrastructures, institutions, networks of actors, etc. Multiple interrelated diffusion processes contribute to the evolution. Adoption and diffusion of technology occurs as a collective evolutionary process. The complex interactions where technologies mutually reinforce and cross-enhance each other drive to the conformation of technological clusters, that is, families of technologies evolving and diffusing together, and the constitution of associated networks of economic and social actors. The members of a cluster are related by multiple links that contribute to magnify their economic, social and environmental impacts. These multiple relations contribute to make progress in one of them relevant, directly or indirectly, to other members of the cluster, as it helps to reinforce their own position in the marketplace (Barreto \& Kemp, 2008).

\section{Conclusions}

Now is the time to reform the energy system, since it was created during the growth phase in a highly industrialized society. Our society is on the verge of an energy crisis and various global environmental problems. These are influences that our society presents great opportunities for technological innovation. To implement this effectively, it is important to conduct and promote energy conservation policies, recognizing the negative effects on the external economy. Wind power has advantages over current systems of high efficiency power generation used today. The great advantage of wind power is the fact that energy can be generated from natural resources that are available and plentiful. However, the electrical energy generated wind power is influenced by natural conditions, which can disturb the stability and reliability. Any escape from this problem of root development cannot be expected. The relationship between the owners of independent wind energy business and its external environment is very difficult. Therefore, it is safe to assume that wind power cannot remain competitive in isolation, as individual business entity with less financial support from consumers of electricity at present. For this question, initially, the government policy and electricity consumers should share the additional costs associated with all aspects of wind energy. As wind generation becomes more widespread, the cost will be reduced through "learning by doing." The more traders contribute to the generation of wind energy that will reduce some of the main disadvantages of the interaction between technology and markets. The advantages that accrue to the consumer as a result of greater penetration of wind power far outweigh the disadvantages of the initial costs.

The analysis of diffusion in the wind energy industry in terms of efficiency, effectiveness and development criteria reveals the following:

1) Internal technological innovation has solved the technological imbalance between the subsystems that constitute a system, thus increasing the performance of wind turbines. These technologies were used in large equipment, improving the efficiency of wind turbines and ensuring economies of scale of this type of equipment in large scale wind farms or wind farms. 
2) For the system of energy businesses, this analysis demonstrated that there is no balance between incentives and contributions from business owners of wind energy, electric energy companies, and consumers. The system is therefore not effective enough now.

3) The system began to evolve in order to complement each other, with systems of other technological products (solar, photovoltaic, etc.) as well as micro-networks.

To highlight these three aspects can be divided into technological trajectory and interaction between technology and markets. Analysis of the criteria of efficiency and technological development shows the trajectory, as described below, in technological innovation. In the first phase, innovations occurred in the subsystems of a product system. Pitch control was adopted in the original draft of Denmark, who became the dominant design. An approach permits the performance of a generator with increasing conversion efficiency of the turbine blades in a complementary relationship. In other words, in a complex product system consisting of interrelated subsystems, it is necessary to increase the integrated action with the parties taking into account the interdependencies with the system, when there is an innovation in a product system. The internal logic of the technology itself defines technological innovation, as stated in the model of Rosenberg's technological imbalance. This case study indicates that not only increases the performance of technological equipment for the imbalance itself, but also creates new technological opportunities to make projects more wind turbines (G. Rosegger, 1996; TPWind, 2010a).

In the second stage, the innovation has occurred at the unit level of a modular product system by adopting a function of change of velocity. When a product system has nonlinear characteristics with respect to the external environment, each party within the modular unit is quite capable of improving the technological imbalances in the face of nonlinear characteristics. For this reason, researchers have turned interference from the external environment in non-interference, which cannot be performed alone, but only through cooperation within the product system with which there was a mutual relationship. Near linear characteristics were obtained, resulting in an increase in the overall performance of the product. In other words, there was awareness of the range in which the imbalance was resolved technological expanded from working out in the modular unit, in search of mutual cooperation and integration has improved the performance of the whole technology (Hobday, 1998; Y. Inoue \& K. Miyazaki., 2008).

In the third stage, the innovation has occurred at the system level and micro-emerging networks. When a disturbance occurs as a frequency shift of power in the electrical system, there are limits that govern the performance improvement, improving the relationship because of the mutual dependence of modular units. For further performance improvement, an alternative means or other technology option is necessary (Heier, 1998). One such measure is to continue with the system decomposition approach in an attempt to stabilize the networks in small groups, ensuring a balance between supply and demand at connection points, and avoid disruptions that occur on the grid in general. It is interesting to note that the evolutionary trajectory of this technology tends to lead to higher levels of the hierarchy of the system for stability (J. Tidd, J. Bessant, \& Pavitt., 2005). This is the reverse, and in contrast to the process by which cars in general and other industries are going to lower levels, apparently due to the fact that the wind carries the full burden of social charges, while generation technologies existing power are not subject to external economic factors. Micro-grids can be expected to affect the diffusion of wind power. If the demand for wind energy grows, the opportunities for technological innovation will emerge as well, which make it possible to eliminate factors that inhibit the rate of technological evolution of wind power (Kim B, 1985).

Analysis of effectiveness and criteria for developments demonstrate the interaction between technology and markets in technological innovation. The case study of the wind energy industry showed that in fields with strong environmental and social characteristics, even if the wind has no economic advantage over existing energy systems, if the benefits are sufficient alternative values are given, it creates opportunities for technological innovation and innovation leads to (IEA, 2010). It was also shown that even induced innovation affect the existing power system in the form of a disturbance, technological innovation occurs as a subsequent variation. Innovations in the wind energy industry are various combinations of trial and error and selections made. The directions of the technology selection tend to high performance and larger systems due to the resolution of an imbalance between the components. As wind energy systems are unstable in isolation, technology selection has been conducted to ensure stability, complementing the product systems (G. Rosegger, 1996). In addition, for a production system to stay competitive, top-level functions of the technological system, that the product system itself is a constituent, must be incorporated into their counterparts in low-level (Figure 10). In doing so, the system differs, resulting in greater autonomy. How the autonomy increases, contributing to increased power generation regionally or locally. 
The process whereby a specific new technology emerges, is improved and diffused in society may be studied using the concept of a technological system, which is a technology-specific innovation system. Due to the technology-specific features of the approach, it is particularly attractive when the focus of enquiry is competition between emerging technologies and incumbent technologies (and between the associated technological systems) (Jacobsson \& Bergek, 2004).

Innovation is the principal source of economic growth and a key source of new employment opportunities and skills, as well as providing potential for realizing environmental benefits. The development and use of new technologies is a systemic process. It occurs in part through basic laboratory research activity, but much innovation also arises within companies active in established markets, and benefits from discoveries and improvements that arise in the course of commercial development, often called 'learning-by-doing'(Foxon et al., 2005).

In recent years, several major economies have implemented political support for various renewable energy technologies, more and more application of market principles, such as technological maturity and reduce the life cycle of products and projects. Spain uses a selling price (feed-in premium) for levels of production and minimum prices for wind energy, while the United Kingdom and Italy have recently introduced band technology in its system of tradable green certificates, which in both cases co-exists with the buying and selling rates fixed. China's support for renewable energy also reflects a combination of different incentives to maturity of different technologies, such as auctions of generation based on onshore wind farms by buying and selling rates for varying levels of clean energy production (IEA, 2008a).

Various steps can be discerned in the life of a technology, from invention through innovation, commercialization, diffusion, saturation, and senescence (the last two stages combined can be referred to as 'maturation'). Still, only two main components of technical change exist: $R \& D$ and learning-by-doing. These occur at different stages of technological evolution. R\&D or RD\&D: research, development and demonstration - mostly takes place at the early stage of technical development, preceding the commercial use of a nascent technology (Sagar \& van der Zwaan, 2006).

For Grubb (2004) innovation is central to tackling climate change, and this paper has sought to review the evidence around the innovation processes relevant to the energy sector, and the implications this may hold for national and international policy responses to climate change. Two big messages emerge.

The first is confirmation that identified technologies do hold the promise of tackling climate change, not through any single 'silver bullet' but through a potentially rich portfolio of options matched to the various major sectors of energy production, conversion, and use. Whether expressed through the "wedges" analysis of about a dozen major options, or through the global system modeling studies, this core and hopeful message is consistent. Yet considerable innovation will be required to sift the options, improve performance and deliver them on a large scale.

Second, the need for innovation is not synonymous with public technology RD\&D expenditure or the hope for blue-skies breakthroughs - the innovation process is altogether more complex, and more interesting. Technologies and systems have to evolve through many stages to build viable and cost-effective low carbon industries out of the seeds - mostly already planted - of low carbon ideas. Engagement with, and investment by, the private sector is critical, but the effective transfer of publicly-funded ideas into the private sector industries remains a big challenge.

\section{References}

Alexandre, J. P. (2001). Energia Eólica: Evolução e Perspectivas Globais. Retrieved November 19, 2008, from http://br.geocities.com/aljappio/images/energiaeolica.htm

Anadon, L. D., \& Holdren, J. P. (2009). Policy for Energy-Technology Innovation. Acting in Time on Energy Policy.

Barreto, L., \& Kemp, R. (2008). Inclusion of technology diffusion in energy-systems models: some gaps and needs. Journal of Cleaner Production, 16(1), S95-S101. http://dx.doi.10.1016/j.jclepro.2007.10.008

Cordeiro, J. (2008). Sumário Executivo [R] evolução Energética. $2^{\mathrm{a}}$ edition. Retrieved November 29, 2008, from http://www.greenpeace.org/brasil/documentos/energia/sumario-executivo-r-evolu-o

D. Mowery, \& Rosenberg, N. (1979). The influence of market demand upon innovation: a critical review of some recent empirical studies. Res. Policy, (8), 103-153.

D. Mowery, \& Rosenberg, N. (1998). Path of Innovation. Cambridge University Press. 
Davies, A., \& Hobday, M. (2005). The Business of Projects. London: Cambridge University Press.

DGGE. (2009). Renováveis - Estatisticas Rápidas novembro/dezembro 2009, $n^{\circ}$ 57/58. Lisboa: DGGE Retrieved from http://www.dgge.pt.

Dismukes, J. P., Miller, L. K., \& Bers, J. A. (2009). The industrial life cycle of wind energy electrical power generation: ARI methodology modeling of life cycle dynamics. Technological Forecasting and Social Change, 76(1), 178-191. http://dx.doi.10.1016/j.techfore.2008.08.011

DTU. (2010). Innovation and Sustainability. Retrieved January 29, 2010, from http://www.man.dtu.dk/English.aspx.

E. Rogers. (1982). Diffusion of Innovation. The Free Press.

EER. (2007). Wind power is competitive. Retrieved January 10, 2010, from http://www.vestas.com/files//Filer/EN/Press_releases/VWS/2007/070110PMUK01EER.pdf

EWEA. (2009b). Wind Energy; The Facts: Part IV Industry and Markets. Retrieved November 3, 2009, from http://wind-energy-the-facts.org/documents/download/Chapter4.pdf

Flavin, C. (1999). Energia Eólica em rápida expansão. Estado do Mundo, 59-61.

Foxon, T. J., Gross, R., Chase, A., Howes, J., Arnall, A., \& Anderson, D. (2005). UK innovation systems for new and renewable energy technologies: drivers, barriers and systems failures. Energy Policy, 33(16), 2123-2137. http://dx.doi.10.1016/j.enpol.2004.04.011

Fri, R. W. (2003). The role of knowledge: technological innovation in the energy system. The Energy Journal, 24(4), 51-74. http://dx.doi.org/10.5547/ISSN0195-6574-EJ-Vol24-No4-3

G. Rosegger. (1996). The economics of production and innovation: an industrial perspective: Pergamon Press.

Gallagher, K. S., Anadon, L. D., Kempener, R., \& Wilson, C. (2011). Trends in investments in global energy research, development, and demonstration. [Review]. Wiley Interdisciplinary Reviews-Climate Change, 2(3), 373-396. http://dx.doi.10.1002/wcc.112

Gallagher, K. S., Holdren, J. P., \& Sagar, A. D. (2006). Energy-Technology Innovation. Annual Review of Environment and Resources, 31(1), 193-237. http://dx.doi.10.1146/annurev.energy.30.050504.144321

Gipe, P. (1995). Wind energy comes of age. New York: John Wiley.

Grubb, M. (2004). Technology Innovation and Climate Change Policy: an overview of issues and options. Keio economic studies, 41(2), 103.

GWEC. (2010). Global Wind 2009 Report First. Retrieved April 04, 2010, from http://www.gwec.net

H.J. Wagner, \& A. Epe. (2009). Energy from wind - perspectives and research needs. The European Physical Journal, 176, 107-114. http://dx.doi.10.1140/epjst/e2009-01151-2

Heier, S. (1998). Grid Integration of Wind Energy Conversion Systems: John Wiley \& Sons.

Hobday, M. (1998). Product complexity, innovation and industrial organization. Policy, 26, 689-710. http://dx.doi.org/10.1016/S0048-7333(97)00044-9

Hughes, T. P. (1983). Networks of Power Electrification in Western Society: Johns Hopkins University Press.

IEA. (2008a). Deploying Renewables: Principles for Effective Policies. Retrieved March 15, 2010, from http://www.iea.org

IEA. (2008b). World Energy Outlook 2008: Executive Summary. Retrieved November 19, 2008, from http://www.iea.org

IEA. (2009). Technology Roadmap: Wind Energy. Retrieved March 20, 2010, from www.iea.org

IEA. (2010). $R \& D$ Trends Worldwide. Retrieved February 2, 2010, from http://www.iea.org

J. Tidd, J. Bessant, \& Pavitt., K. (2005). Managing Innovation Integrating Technological, Market and Organizational Change. John Wiley \& Sons.

Jacobsson, S., \& Bergek, A. (2004). Transforming the energy sector: the evolution of technological systems in renewable energy technology. Industrial and Corporate Change, 13(5), 815-849. http://dx.doi.org/10.1093/icc/dth032

Kaldellis, J. K., \& Zafirakis, D. (2011). The wind energy (r)evolution: A short review of a long history. Renewable Energy, 36(7), 1887-1901. http://dx.doi.10.1016/j.renene.2011.01.002 
Kim B, C. (1985). The interaction of design hierarchies and market concepts in technological evolution. Research Policy, 14(5), 235-251. http://dx.doi.10.1016/0048-7333(85)90007-1

Kobos, P. H., Erickson, J. D., \& Drennen, T. E. (2006). Technological learning and renewable energy costs: implications for US renewable energy policy. Energy Policy, 34(13), 1645-1658. http://dx.doi.10.1016/j.enpol.2004.12.008

Loiter, J. M., \& Norberg-Bohm, V. (1999). Technology policy and renewable energy: public roles in the development of new energy technologies. Energy Policy, 27(2), 85-97. http://dx.doi.10.1016/s0301-4215(99)00013-0

Markard, J., \& Truffer, B. (2006). Innovation processes in large technical systems: Market liberalization as a driver for radical change? Research Policy, 35(5), 609-625. http://dx.doi.org/10.1016/j.respol.2006.02.008

Miketa, A., \& Schrattenholzer, L. (2004). Experiments with a methodology to model the role of R\&D expenditures in energy technology learning processes; first results. Energy Policy, 32(15), 1679-1692. http://dx.doi.10.1016/s0301-4215(03)00159-9

Mohan Reddy, N., Aram, J. D., \& Lynn, L. H. (1991). The institutional domain of technology diffusion. Journal of Product Innovation Management, 8(4), 295-304. http://dx.doi.10.1016/0737-6782(91)90050-9

Nakicenovic, N. (1998). Global Energy Perspectives. Cambridge, UK: Cambridge University Press.

Neij, L. (1997, May 28-29). Experience curves and the di!usion of solar cells and wind power. Paper presented at the Technological and Industrial Renewal of the Energy Sector, Sweden.

Neij, L. (2008). Cost development of future technologies for power generation-A study based on experience curves and complementary bottom-up assessments. Energy Policy, 36(6), 2200-2211. http://dx.doi.10.1016/j.enpol.2008.02.029

Nick Loney. (2001). The Windicator - Operational Wind Power Capacity Worldwide. Wind Power Monthly.

Ortt, J. R., \& van der Duin, P. A. (2008). The evolution of innovation management towards contextual innovation. European Journal of Innovation Management, 11(4), 522-538. http://dx.doi.org/10.1108/14601060810911147

Rao, K. U., \& Kishore, V. V. N. (2010). A review of technology diffusion models with special reference to renewable energy technologies. Renewable and Sustainable Energy Reviews, 14(3), 1070-1078. http://dx.doi.10.1016/j.rser.2009.11.007

Robert D. Perlack, \& Shelton., R. B. (1996). Government's Role in Energy Technology R\&D; A Proposed Model for Strategic Guidance. (ORNL/TM-13218). Oak Ridge National Laboratory.

Sagar, A. D., \& van der Zwaan, B. (2006). Technological innovation in the energy sector: R\&D, deployment, and learning-by-doing. [Article]. Energy Policy, 34(17), 2601-2608. http://dx.doi.10.1016/j.enpol.2005.04.012

Schilling, M. A., \& Esmundo, M. (2009). Technology S-curves in renewable energy alternatives: Analysis and implications for industry and government. Energy Policy, 37(5), 1767-1781. http://dx.doi.10.1016/j.enpol.2009.01.004

SunMedia GmbH. (1999). Wind Turbine Market: Types, Technical Characteristics: Prices.

TPWind. (2010a). Strategic Research Agenda. Retrieved April 20, 2010, from http://www.windplatform.eu/

TPWind. (2010b). European Technology Platform for Wind Energy. Retrieved April 20, 2010, from http://www.windplatform.eu/

Vesterdal, J. (1992). The Potential of Wind Farms: ELSAM.

Y. Inoue, \& K. Miyazaki. (2008). Technological innovation and diffusion of wind power in Japan. Technological Forecasting \& Social Change, 75, 1303-1323. http://dx.doi.10.1016/j.techfore.2008.01.001

Zervos, A., \& Kjaer, C. (2008, November 27). Wind Energy Scenarios up to 2030. Pure Power. 
Table 1. Thematic areas with R\&D focus for wind energy by TPWind

\begin{tabular}{|c|l|}
\hline Thematic areas & \multicolumn{1}{c|}{ Focus } \\
\hline Wind conditions & $\begin{array}{l}\text { Develop more efficient methods for determining wind resources and identifying regions } \\
\text { rich in poorly-exploited wind resources, in order to enable increased and more } \\
\text { cost-effective wind farm assets. Key areas in this thematic may include: advanced sitting } \\
\text { and wind characterization models. Wind resource mapping, advanced wind power } \\
\text { forecasting techniques. Advanced measurements techniques including remote sensing. }\end{array}$ \\
\hline $\begin{array}{c}\text { Wind power } \\
\text { systems }\end{array}$ & $\begin{array}{l}\text { Aspects of wind turbine technology, both offshore and onshore, which have the potential to } \\
\text { increase the competitiveness of wind energy, and to minimize the lifetime cost of } \\
\text { electricity generated by wind power systems. Key areas in this thematic may include: } \\
\text { Materials, Drive-trains, Blades, O\&M and Wind turbine design and efficiency increase. }\end{array}$ \\
\hline $\begin{array}{c}\text { Wind energy } \\
\text { integration }\end{array}$ & $\begin{array}{l}\text { Large-scale integration of wind power (300 GW), by enabling high penetration levels } \\
\text { (>20\%) with low integration costs, while maintaining system reliability (security of } \\
\text { electricity supply). Key areas in this thematic may include: Grid codes/communication } \\
\text { standards, Grid structure and planning, Grid operation and energy management } \\
\text { (prediction tools, probabilistic capacity planning, and storage facilities), Energy market } \\
\text { integration (converting stochastic wind energy production into energy market products, } \\
\text { providing additional grid services to TSO's and DSO's). }\end{array}$ \\
\hline $\begin{array}{c}\text { Offshore } \\
\text { operations }\end{array}$ & $\begin{array}{l}\text { R\&Ding and innovation for offshore wind energy. Key areas in this thematic may include: } \\
\text { safety and access to offshore turbines, new and improved concepts for offshore wind } \\
\text { turbines, design and fabrication of offshore substructures, new concepts for assembly } \\
\text { installation and hookup of large scale developments, offshore cables and connectors, } \\
\text { operations and maintenance, spatial planning and decommissioning. }\end{array}$ \\
\hline
\end{tabular}

Source: Strategic Research Agenda (TPWind, 2010a) 
TOP 10 CUMULATIVE INSTALLED CAPACITY 2009

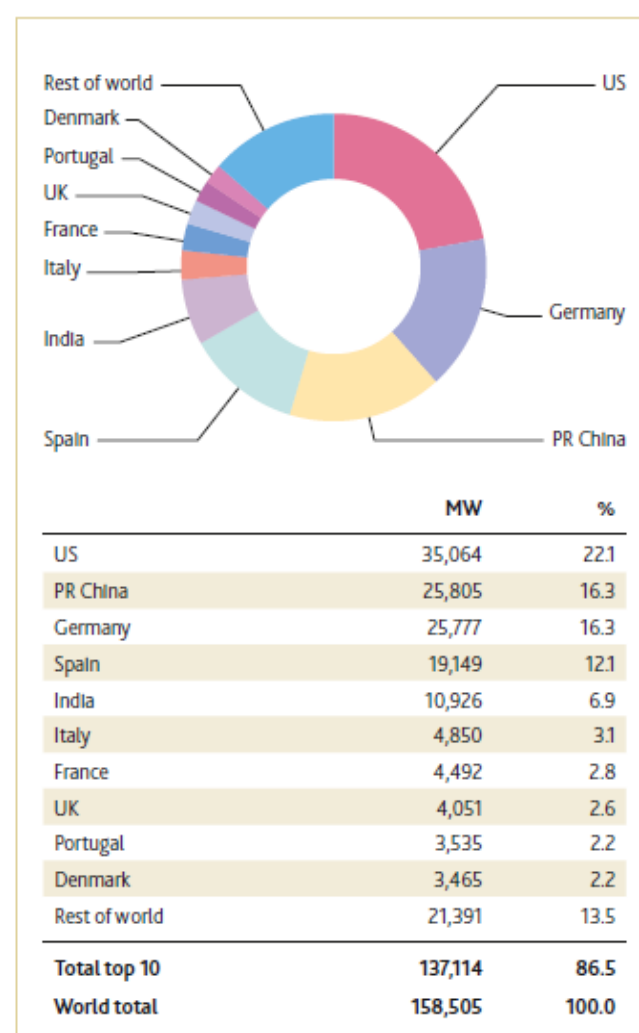

TOP 10 NEW INSTALLED CAPACITY 2009

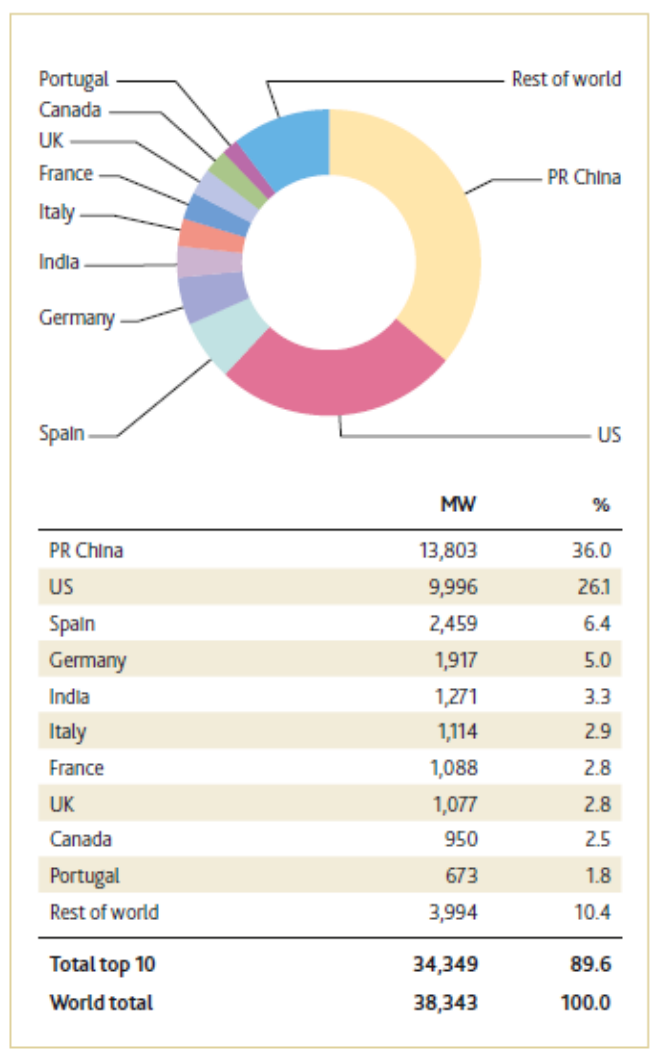

Figure 1. Global Cumulative Installed Capacity / Top 10 New Installed Capacity (MW) (GWEC, 2010)

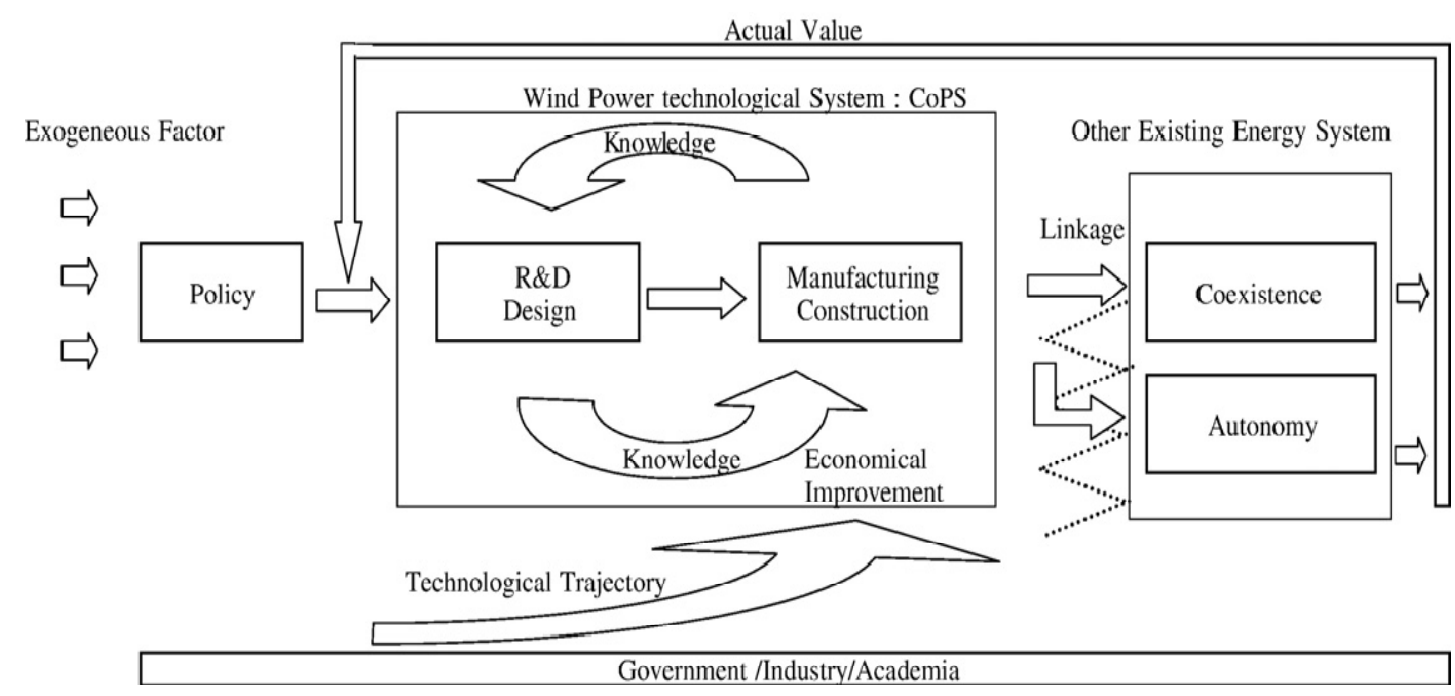

Figure 2. Diffusion model for wind power generation system (Y. Inoue \& K. Miyazaki., 2008) 


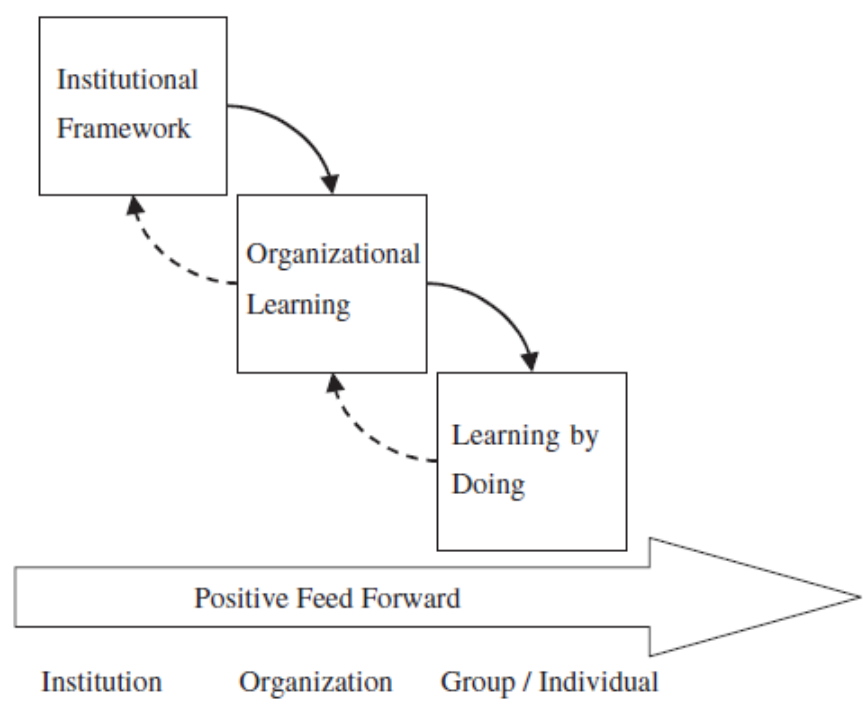

Figure 3. A dynamic process of organizational learning (Kobos, et al., 2006)

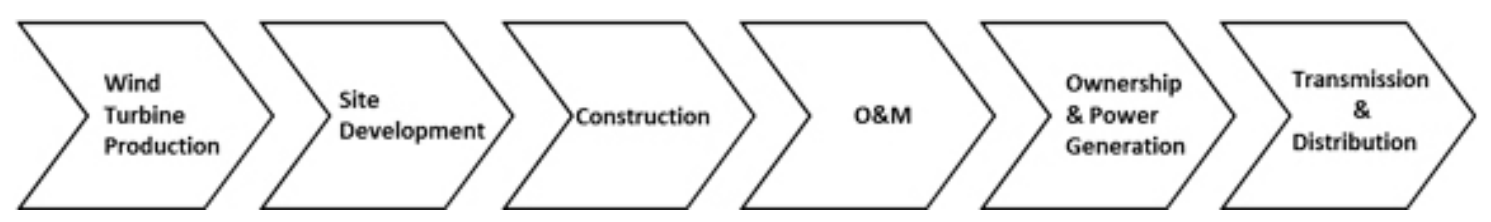

Figure 4. Wind energy industry value chain (EER, 2007)

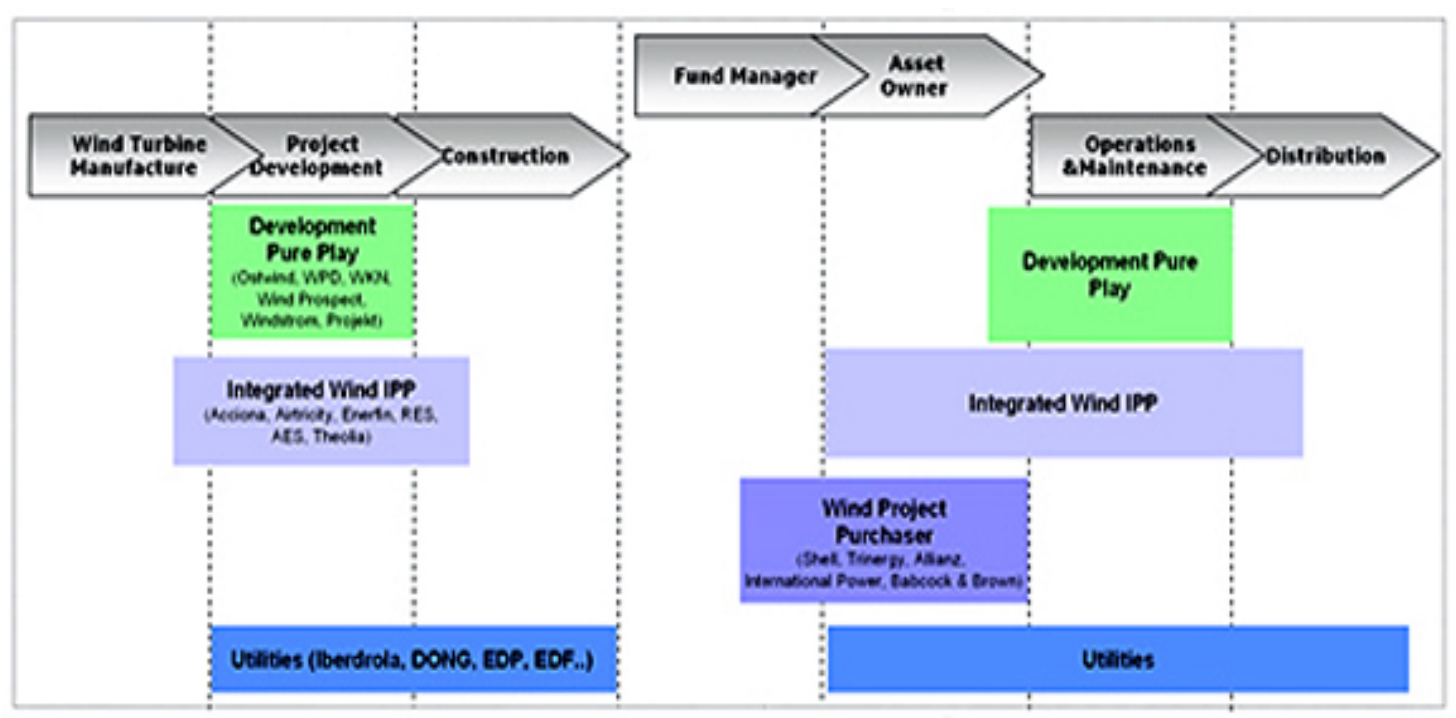

Figure 5. Europe wind value chain positioning (EER, 2007)

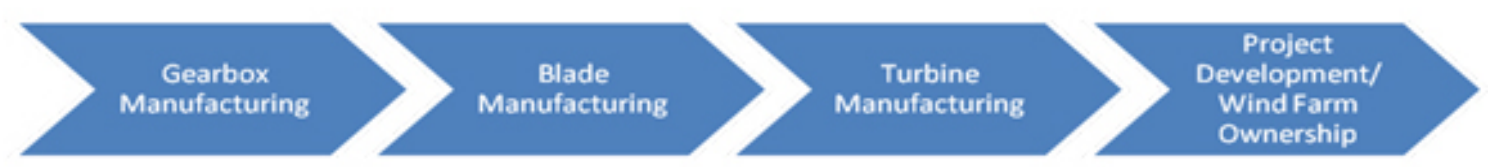

Figure 6. Value chain - production of wind components (EER, 2007) 


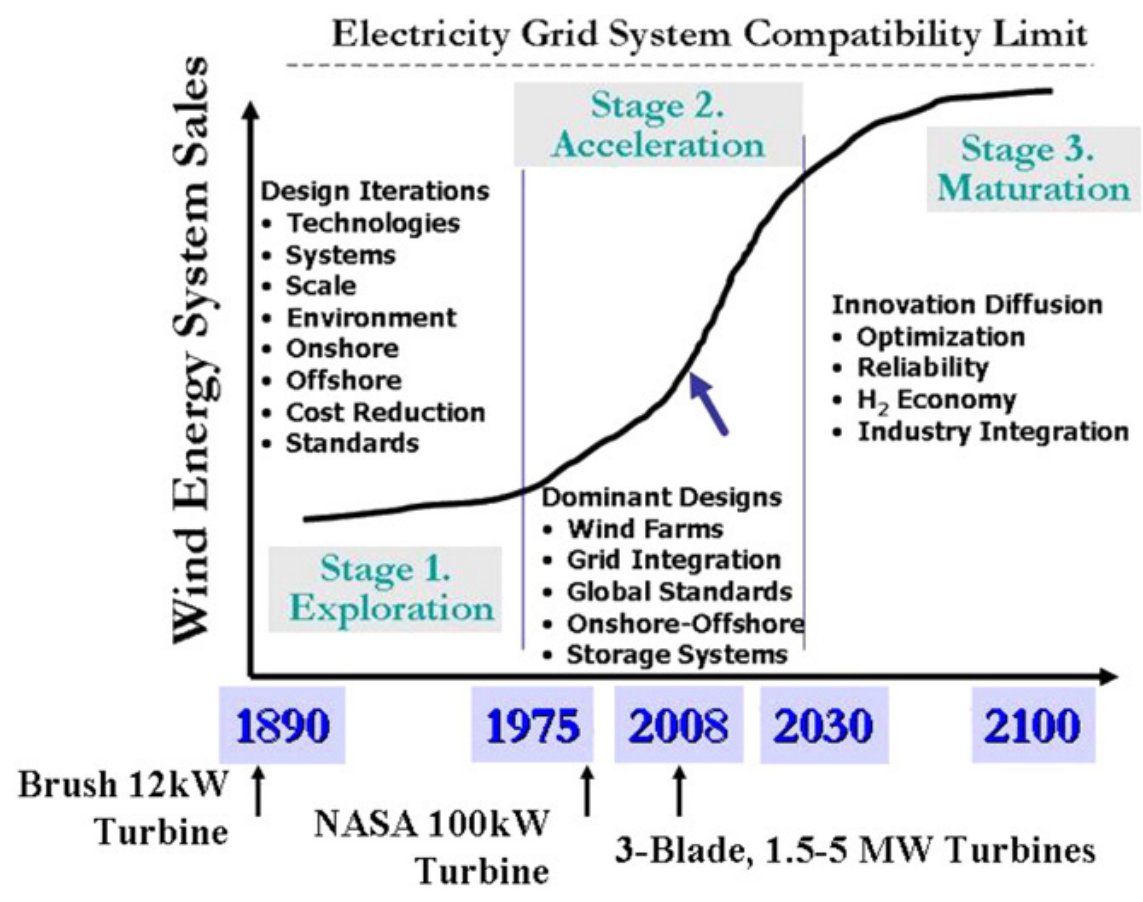

Figure 7. Wind energy technological innovation - projected 210 years industrial technology life cycle

(Dismukes, Miller, \& Bers, 2009)

\section{Box 2. Technology development stages}

R\&D seeks to overcome technical barriers and to reduce costs. Commercial outcomes are highly uncertain, especially in the early stages.

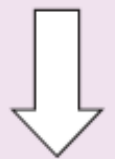

In the demonstration stage, the technology is demonstrated in practice. Costs are high. External (including government) funding may be needed to finance part or all of the costs of the demonstration.

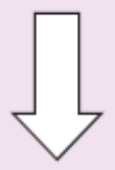

RETs at the deployment stage operate successfully technically, but may still be in need of support to overcome cost or non-cost barriers. With increasing deployment, technology learning will progressively decrease costs.

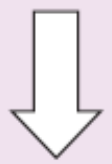

Diffusion/ Commercialisation: The technology is cost competitive in some or all markets, either on its own terms or, where necessary, supported by government intervention (e.g. to value externalities such as the costs of pollution).

Figure 8. Stages of the technological process in the wind energy industry (IEA, 2010) 


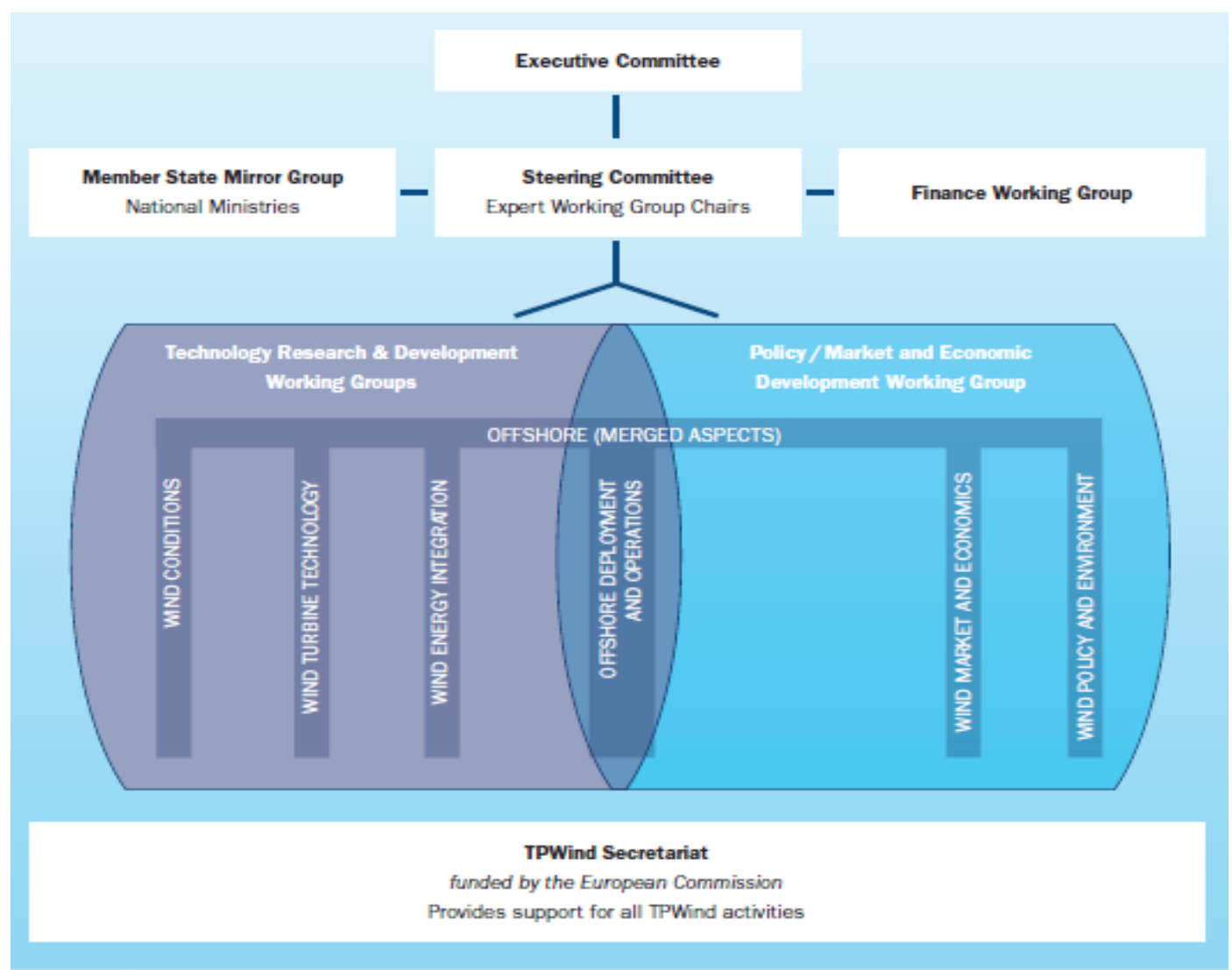

Figure 9. TPWind organizational structure (TPWind, 2010b)

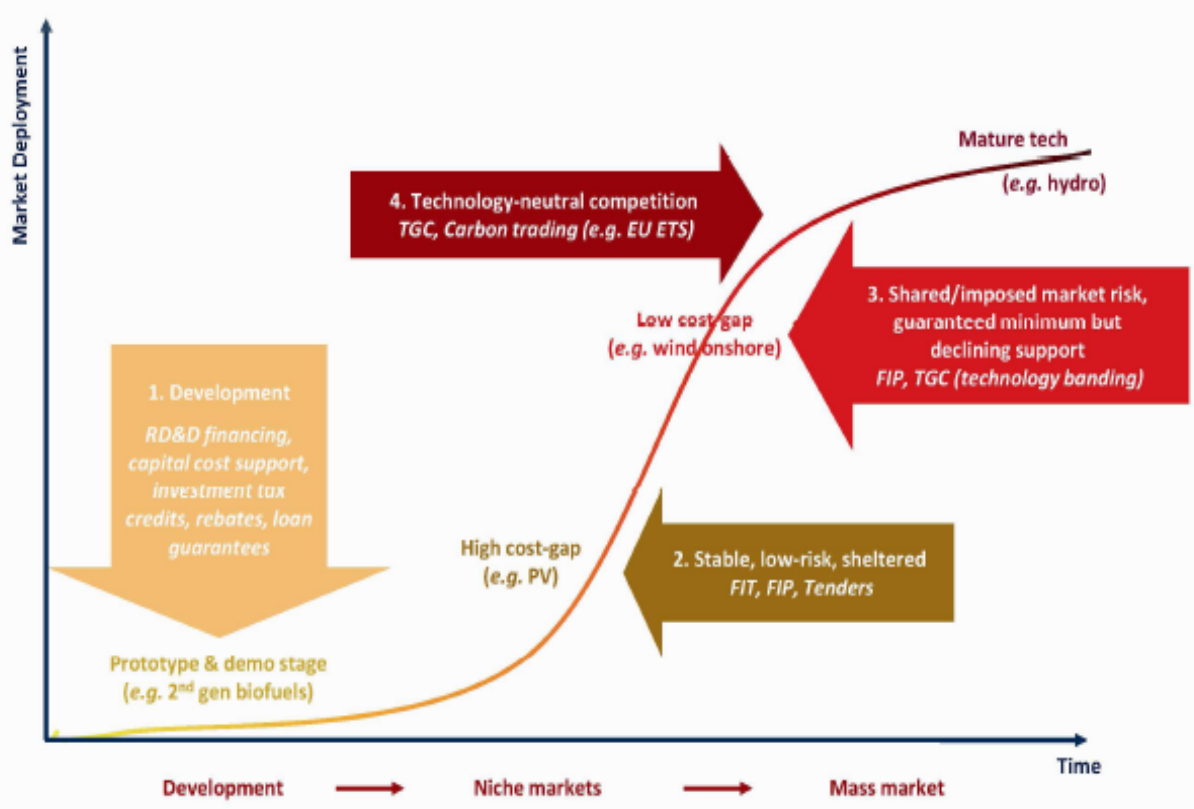

Legend: FIT = feed-in tariff; FIP = feed-in premium; TGC = tradable green certificate; EU ETS = European Union Emission Trading Scheme

Figure 10. Technology integration to the market (IEA, 2010) 